\title{
Caso clínico: infección del sitio quirúrgico en una paciente recomendada
}

Clinical case: surgical site infection in a recommended patient

José Manuel Pérez-Atanasio*

* Médico ortopedista, maestro en Ciencias. Coordinador de investigación

del Hospital Shriners para Niños de la Ciudad de México.

Correspondencia: Dr. José Manuel Pérez Atanasio. Av. Del Imán No. 257, Pedregal de Santa Úrsula, Alcaldía Coyoacán, 09820, CDMX. Correo electrónico: drmanuelperezata@gmail.com

\section{PRESENTACIÓN DEL CASO}

Se trata de paciente femenino de 65 años de edad con antecedente de obesidad, diabetes de 10 años de diagnóstico, hipertensión arterial de 15 años de diagnóstico; ambas enfermedades con mal apego al tratamiento médico.

A las 11:00 de la mañana, acudió al Área de Urgencias del Hospital General Regional y solicitó ser atendida de manera expedita por un especialista, ya que había sufrido una «torcedura de tobillo» cuando salía de bañarse, aproximadamente 30 minutos antes de su llegada.

La asistente médica la recibió en ventanilla y le solicitó su documentación de identificación para comprobar su vigencia de derechos en la institución, a lo cual la paciente respondió: «¿No sabe quién soy? Soy la tía del delegado». La asistente médica, al no saber cómo actuar, buscó al jefe del Servicio de Ortopedia, quien acudió al Área de Urgencias y certificó que efectivamente se trataba de la tía del señor delegado, pues la conocía personalmente.

Inmediatamente la atendió y solicitó una radiografía de tobillo, en la que se observó una fractura del mismo (Figura 1).

El jefe de servicio, con el afán de mostrar eficiencia en la atención, indicó al médico residente que realizara de manera inmediata el ingreso y las hojas de programación quirúrgica para que se operara a la brevedad.

Se designó como médico tratante al Dr. Pérez, ortopedista del turno vespertino. El jefe de servicio le solicitó operar a la paciente, quien fue presentada sólo por sus antecedentes de relación familiar con el delegado y no por su cuadro clínico ni por sus antecedentes médicos.

El médico tratante, quien quería quedar bien con su jefe para que le autorizara sin restricciones sus vacaciones, pasó a quirófano a la mujer e inició la cirugía sin verificar si contaba 
con el material quirúrgico necesario, sin ver los resultados de los estudios de laboratorio que mostraban un nivel de glucosa en sangre de $500 \mathrm{mg} / \mathrm{dl}$ y $\mathrm{sin}$ indicar la aplicación de una dosis de antibiótico profiláctico.

Durante la cirugía, ya con la disección hasta el trazo de fractura, el cirujano solicitó el material de osteosíntesis, a lo cual la enfermera instrumentista le informó que no tenía lo solicitado, por lo que esperaron más de 30 minutos hasta contar con él.

En el periodo postoperatorio a solicitud expresa de la paciente, fue dada de alta en cuanto se recuperó de la anestesia, sin un control de los niveles de glucosa en sangre.

Cinco días posteriores a la cirugía, acudió la paciente al Área de Urgencias con fiebre, edema en el tobillo, aumento de la temperatura local y exudado purulento a través de la herida quirúrgica.

\section{ANÁLISIS}

En este caso se presentaron una serie de acciones y omisiones que incrementaron el riesgo de presentar una infección del sitio quirúrgico, tales como: no tener un control adecuado de los niveles glucémicos, incremento innecesario del tiempo quirúrgico por esperar el material de osteosíntesis (el cual no fue verificado antes de empezar la cirugía), manejo deficiente del antibiótico profiláctico y la falta del seguimiento estrecho de la evolución postquirúrgica del paciente.

La actuación del personal de salud no se apegó a lo recomendado en:

- Guía para la prevención de la infección del sitio quirúrgico de la Organización Mundial de la Salud. ${ }^{1}$

- Guía de Práctica Clínica para la prevención y diagnóstico de la infección del sitio quirúrgico del Instituto Mexicano del Seguro Social. ${ }^{2}$

A pesar de que el personal de salud conoce las guías mencionadas, no siempre se apegan a sus recomendaciones. Al reflexionar sobre las causas subyacentes del porqué se presentaron tantos errores de manera sistemática en la atención de la paciente, considero que pudo influir el "síndrome del recomendado", que de acuerdo a Rubiales, se manifiesta como la aparición de imprevistos y complicaciones no habituales en pacientes con los que se pretende desarrollar una atención con mayor esmero. ${ }^{3,4}$

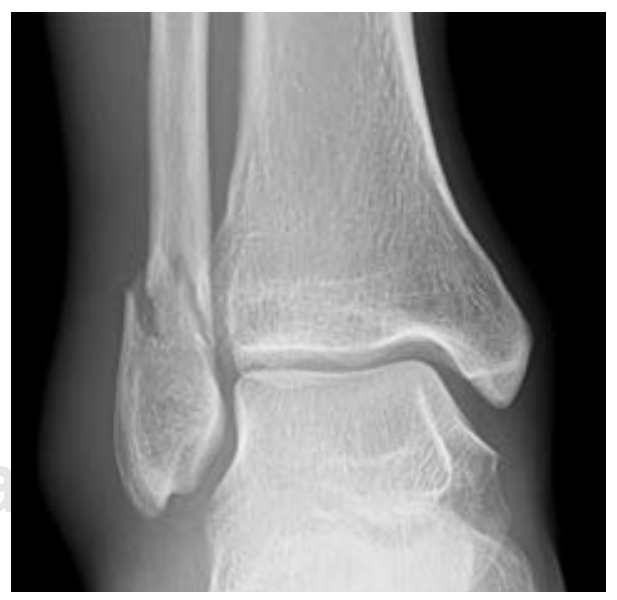

Figura 1: Imagen radiográfica anteroposterior de tobillo. 
Este síndrome, no reconocido oficialmente hasta el momento por ninguna institución de salud, se presenta en la actividad hospitalaria cotidiana y deriva de alguna de las siguientes acciones:

- Solicitud de una atención especial por parte de los pacientes.

- Desorden en el empleo de los recursos sanitarios.

- Mala calidad en el registro de datos; extravío o fragmentación de la historia clínica.

- Ausencia de líneas comunes de actuación y de liderazgo en el personal sanitario.

- Exceso de estudios diagnósticos con los consiguientes «falsos positivos».

- Omisión de estudios sencillos habituales.

- Sobretratamiento o iatrogenia. ${ }^{3}$

El hecho de capacitar al personal sanitario en la prevención de la infección del sitio quirúrgico no garantiza que al momento de estar frente a un paciente actúen como es deseado, por lo que se recomienda actuar con todos los pacientes en apego a las buenas prácticas clínicas, independientemente de su condición socioeconómica o grado de influencia. No ser presionado para dar una atención expedita, la cual puede implicar la omisión de procesos que previenen el desarrollo de la infección del sitio quirúrgico.

Asimismo, se debe actuar siempre, con todos los pacientes, en apego a un protocolo estandarizado y fundamentado en el conocimiento científico, protege del desarrollo de complicaciones prevenibles.

\section{BIBLIOGRAFÍA}

1. Global Guidelines for the Prevention of the Surgical Site Infection. World Health Organization. 2016.

2. Prevención y diagnóstico de la infección del sitio quirúrgico. Guía de Evidencias y Recomendaciones: Guía de Práctica Clínica. México, Instituto Mexicano del Seguro Social; 2018. Disponible en: http:/l imss.gob.mx/profesionales-salud/gp.

3. Sanz RA, Del Valle RM, Flores PL, Hernansanz CS, García RC, López-Lara MF. Síndrome del recomendado. An Med Interna (Madrid). 2002; 19 (8): 430-433.

4. Young P, Finn BC, O’Farrell ML, Ceballos ME, Bruetman JE. Síndrome del recomendado. Rev Med Chile. 2012; 140: 1365-1366.

Nota aclaratoria: el presente caso clínico es ficticio, no hace alusión a ninguna persona en específico y sólo sirve de ejemplo ilustrativo con fines académicos. 